\title{
Estado da arte sobre pesquisa escolar no Brasil
}

\author{
The state-of-the-art of the research process in Brazil
}

landara Reis de OLIVEIRA'

Bernadete Santos CAMPELLO'

\section{Resumo}

Investigações sobre pesquisa escolar em escolas de ensino básico no Brasil têm se desenvolvido em áreas como Biblioteconomia/ Ciência da Informação, Educação e Letras. O objetivo deste trabalho foi estabelecer o estado da arte da investigação sobre pesquisa escolar no Brasil. A metodologia foi a análise documental de 24 relatos de pesquisa, cobrindo o período de 1989 a 2011, sendo treze relatos provenientes da área de Biblioteconomia/Ciência da Informação, sete de Educação, dois de Engenharia de Produção e dois de Letras. Verificou-se uma contradição entre discurso e prática: havia compreensão teórica da pesquisa como princípio educativo, mas na maioria das vezes isso não foi suficiente para viabilizá-la como prática escolar eficiente, sendo que a maioria dos estudos identificou aspectos negativos relacionados à pesquisa escolar.

Palavras-chave: Aprendizagem. Biblioteca escolar. Pesquisa e informação. Pesquisa escolar.

\begin{abstract}
Studies on the research process in Brazilian schools have been conducted in different areas such as Library/Information Science, Education and Literature. The aim of this study was to establish the state-of-the-art of investigation on the research process in Brazil, covering all fields. The methodology consisted of document analysis of 24 academic documents from 1989 to 2011, of which thirteen were in the field of Library/Information Science, seven in Education, two in Production Engineering, and two in Literature. The analysis showed a contradiction between discourse and practice: studies point out that the theoretical understanding of the research process as an educational principle were present, but they indicate that this understanding was not enough to make it feasible as an effective school practice and most studies identified negative aspects related to the research process.
\end{abstract}

Keywords: Learning. School library. Research and information. Educational research.

\section{Introdução}

A aprendizagem pela pesquisa constitui um tema importante para bibliotecários, já que a biblioteca é pretensamente local que reúne materiais necessários para a busca por informações, atividade que embasa (ou deveria embasar) o processo de pesquisa. O tema ficou em evidência na Biblioteconomia a partir do movimento de renovação do ensino que preconiza a utilização de métodos ativos de aprendizagem, considerando o aluno como responsável pela construção de seu conhecimento. $\mathrm{O}$ ensino em bases construtivistas dá oportunidade para que a biblioteca exerça, de maneira mais clara, sua ação educativa (Campello, 2003). Na verdade, estratégias construtivistas de aprendizagem se apoiam, ou deveriam se apoiar, no uso de variadas fontes de informação, e há expectativa de que a biblioteca constitua local privilegiado para a realização da pesquisa escolar,

\footnotetext{
1 Universidade Federal de Minas Gerais, Escola de Ciência da Informação, Programa de Pós-Graduação em Ciência da Informação. Av. Pres. Antônio Carlos 6627, Pampulha, 31270-901, Belo Horizonte, MG, Brasil. Correspondência para/Correspondence to: B.S. CAMPELLO. E-mail: <bscampello@gmail.com>.

Recebido em 14/7/2014, reapresentado em 2/7/2015 e aceito para publicação em 4/8/2015.
} 
mesmo no momento em que a Internet parece ser a fonte preferida de busca de informações (Burlamaqui, 2007; Abe, 2009; Diedrich, 2009; Teixeira, 2011).

Desde a década de 1960, a Biblioteconomia vem expressando preocupação com a pesquisa escolar (Campello, 2003), visualizando-se três perspectivas distintas sobre o tema na literatura da área. Na primeira, os textos revelam o discurso de bibliotecários que chamam a si a responsabilidade pelo desenvolvimento de uma gama de habilidades cognitivas nos estudantes e que se mostram claramente conscientes de seu papel no processo inovador de aprendizagem. A fala de Santos (1973) exemplifica essa perspectiva:

\begin{abstract}
A biblioteca [...] estará em conjunção com a nova pedagogia da leitura, transformando-se num centro de documentação, incluindo, além dos livros, o material audiovisual utilizado por professores e alunos. Esta é a biblioteca que se integraria no ensino pregado pela nova pedagogia, que viria a personalizar a vida da escola. Para tal deveria transformar o bibliotecário comum num verdadeiro especialista da pedagogia da pesquisa e da leitura. Um bibliotecário que se relacionasse, como tal, com os diretores, os professores e os demais responsáveis pelos serviços educativos, para que pudesse delinear com segurança os métodos que permitissem à biblioteca atender aos objetivos da pedagogia moderna (Santos, 1973, p.175).
\end{abstract}

Na segunda perspectiva, situam-se poucos trabalhos que, indo além do discurso sobre a importância da pesquisa escolar, propõem atividades sistemáticas para ensinar os alunos a usar a biblioteca e as fontes de informação, preparando-os para as tarefas da pesquisa (Bejes \& Dias, 1973; Carvalho, 1981; Cuartas \& Gatti, 1982; Laan \& Ferreira, 1991; Kuhlthau, 2010).

Uma terceira perspectiva surgiu com a criação de cursos de Pós-Graduação em Biblioteconomia na década de 1970, o que ensejou a pesquisa na área e a consequente produção bibliográfica (Campello et al., 2007). No que diz respeito especificamente ao tema da pesquisa escolar, o primeiro estudo acadêmico identificado foi a dissertação de Ana Maria Nogueira Machado, de 1989, com o sugestivo título de Pesquisa escolar: uma questão para resolver, defendida no Curso de Pós-Graduação em Biblioteconomia da Pontifícia Universidade Católica de Campinas.
Desde então, nos últimos 20 anos, embora em pequena quantidade, os estudos sobre pesquisa escolar vêm sendo realizados de forma regular nos cursos de Pós- Graduação em Biblioteconomia/Ciência da Informação, propiciando maior entendimento da questão.

Mesmo realizadas no âmbito da Ciência da Informação, as investigações têm buscado referenciais em autores da área de Educação, sendo Pedro Demo um dos mais citados. A proximidade das duas áreas, no que diz respeito à preocupação com a pesquisa escolar, é reforçada pelas investigações estrangeiras mais recentes da Ciência da Informação, que, além de estudar o processo propriamente dito (Filipenko, 2004; Kuhlthau, 2004) têm privilegiado temáticas tais como motivação (Crow, 2009; Arnone et al., 2010) e colaboração professor/bibliotecário (Montiel-Overall, 2005; Haycock, 2007), considerando que a pesquisa escolar é bem sucedida quando conta com a mediação conjunta desses dois profissionais (Harada, 2005; Williamson et al., 2010), fato esse que reforça a importância do diálogo entre a Educação e a Ciência da Informação.

Portanto, é necessário analisar como a pesquisa escolar tem sido investigada nas duas áreas e que resultados vêm sendo obtidos, possibilitando verificar falhas e omissões e conhecer evidências que permitam propor soluções para a melhoria do processo.

O objetivo deste trabalho foi, portanto, estabelecer o estado da arte da investigação sobre pesquisa escolar no Brasil, traçando um panorama do conhecimento sobre o tema.

\section{Procedimentos metodológicos}

Para alcançar o objetivo proposto, foi escolhida a metodologia de pesquisa documental, analisando-se relatos de pesquisa sobre o tema, representados por teses e dissertações defendidas em programas de Pós-Graduação, artigos de periódicos e trabalhos de eventos.

A identificação dos relatos que compuseram o corpus de análise foi feita na base de dados Literatura Brasileira em Biblioteca Escolar (LIBES), que inclui documentos publicados desde a década de 1960 sobre biblioteca escolar, no Portal de Periódicos Capes e no Portal SciELO, utilizando-se os termos: pesquisa escolar, 
projetos, projeto de pesquisa, trabalho com projetos, projetos de trabalho.

A seleção dos relatos foi feita com base na existência de elementos que caracterizam o texto científico, conforme síntese elaborada por Oliveira e Queiroz (2015), garantindo sua natureza de relato de pesquisa.

Outros critérios para escolha foram: relatos cujos dados empíricos tenham sido coletados no âmbito do ensino básico e disponíveis em texto completo. Ao final, compuseram o corpus de análise 24 documentos, cobrindo um período de 23 anos, de 1989 a 2011. As características desses documentos, em ordem cronológica, são apresentadas no Quadro 1.

\section{Resultados e Discussão}

Os relatos analisados cobriram um período de 22 anos (de 1989 a 2011), percebendo-se que só em 1997 teve início uma produção mais regular, porém exígua, chamando atenção os anos de 2004 (4 relatos), 2008 (3 relatos) e 2009 (3 relatos): nesses três anos foram produzidos 41,6\% do total dos estudos. Assim, uma produção que parecia aumentar caiu novamente para um relato por ano em 2010 e 2011.

Considerando-se o gênero textual, foram 17 dissertações, quatro artigos de periódico, três trabalhos de evento e uma tese. As dissertações perfizeram 70,8\% do total dos relatos, fato que pode ser relacionado à autoria, que foi individual em 80,3\% dos casos.

No que diz respeito à área, houve predominância da Biblioteconomia/Ciência da Informação com 54,2\% (13) dos relatos, seguida da Educação com sete (29,2\%) relatos. Há duas dissertações (8,3 \%) produzidas em cursos de Engenharia de Produção, cujas autoras são bibliotecárias, e duas da área de Letras (8,3\%), sendo as quatro com referencial teórico baseado principalmente na Educação. Ressalta-se que só em 2004 o tema apareceu fora da Biblioteconomia/Ciência da informação.

A biblioteca constituiu o foco de 15 estudos, 13 dos quais na área de Biblioteconomia/Ciência da Informação e dois de Engenharia de Produção. Nos restantes nove estudos (7 da área de Educação e 2 de Letras), a biblioteca foi mencionada esporadicamente, aparecendo como espaço que reunia os materiais para a pesquisa e que vem sendo substituída pela Internet na preferência dos alunos. A ausência e a precariedade da biblioteca e seu pouco uso por estudantes e professores também foram mencionadas, assim como a dificuldade dos alunos em usar as fontes de informação adequadamente. Em dois estudos, a biblioteca não apareceu, sendo a pesquisa escolar estudada na perspectiva da sala de aula e do laboratório de informática.

\section{Características dos dados empíricos}

O número de ambientes pesquisados, escola ou biblioteca, variou de um a 22. A maioria dos estudos (14) coletou dados em apenas um ambiente; um estudo não mencionou a quantidade de ambientes. As instituições públicas (escolas e/ou bibliotecas) aparecem em maior número: foram 17 instituições públicas (7 escolas, 8 bibliotecas escolares e 2 bibliotecas públicas) e 12 particulares (8 escolas e 4 bibliotecas escolares).

Os sujeitos foram: os estudantes (19 estudos), seguidos pelos professores (14 estudos) e bibliotecários (8 estudos). Em menor proporção, foram ouvidos os dirigentes (3), o pessoal da biblioteca (3), membros da equipe pedagógica (2) e pessoal do laboratório de informática (2). O número de sujeitos variou de 6 a 1 040, nos 21 estudos que descreveram claramente os participantes. Em 3 estudos esse número não foi explicitado ou foi mencionado de forma ambígua. Apenas 5 estudos tiveram mais de 100 sujeitos participantes.

A escuta dos sujeitos foi feita principalmente por meio de entrevistas (utilizadas em 15 estudos) e questionários (13 estudos). Nove estudos usaram a técnica naturalística de observação, com registro em diários. Foram também usadas a análise do produto final (4 estudos), análise documental (2) e grupo focal (1). A análise dos dados foi realizada predominantemente por meio de descrições, sendo que três estudos indicaram claramente que utilizaram a técnica de análise de discurso, enquanto outro utilizou um software específico de análise. Onze estudos apresentaram os dados na forma de porcentagens simples.

Como resultado, os trabalhos selecionados apontaram: Malogro da pesquisa escolar como estratégia didática; Falta de questionamento e debates acerca do objeto da pesquisa; Falta de motivação do aluno para a 
Quadro 1. Características dos relatos em ordem cronológica.

\begin{tabular}{|c|c|c|c|c|c|}
\hline Título & Autoria & Ano & $\begin{array}{l}\text { Forma de } \\
\text { publicação }\end{array}$ & Área & $\begin{array}{c}\text { Origem } \\
\text { (curso, periódico ou evento) }\end{array}$ \\
\hline $\begin{array}{l}\text { 1) Pesquisa escolar: uma } \\
\text { questão para resolver. }\end{array}$ & $\begin{array}{l}\text { MACHADO, Ana Maria } \\
\text { Nogueira }\end{array}$ & 1989 & Dissertação & Biblioteconomia & $\begin{array}{l}\text { Faculdade de Biblioteconomia, } \\
\text { Pontifícia Universidade Católica } \\
\text { de Campinas. }\end{array}$ \\
\hline $\begin{array}{l}\text { 2) Processo educativo na } \\
\text { mediação da informa- } \\
\text { ção em biblioteca pú- } \\
\text { blica: um estudo feno- } \\
\text { menológico. }\end{array}$ & $\begin{array}{l}\text { MARTUCCI, Elizabeth } \\
\text { Márcia }\end{array}$ & 1997 & Artigo & Biblioteconomia & $\begin{array}{l}\text { Revista de Biblioteconomia de } \\
\text { Brasília. }\end{array}$ \\
\hline $\begin{array}{l}\text { 3) Pesquisa na biblioteca } \\
\text { escolar: a eficiência de } \\
\text { um roteiro. }\end{array}$ & $\begin{array}{l}\text { PÉCORA, Gláucia Maria } \\
\text { Mollo }\end{array}$ & 1998 & Dissertação & Biblioteconomia & $\begin{array}{l}\text { Faculdade de Biblioteconomia, } \\
\text { Pontifícia Universidade Católica } \\
\text { de Campinas. }\end{array}$ \\
\hline $\begin{array}{l}\text { 4) Diagnóstico da pesqui- } \\
\text { sa escolar no ensino de } \\
5^{\text {a a }} 8^{\text {a }} \text { série do } 1^{\circ} \text { grau, } \\
\text { nas escolas de Londri- } \\
\text { na, Paraná. }\end{array}$ & $\begin{array}{l}\text { OLIVEIRA, Sônia Maria } \\
\text { Marques, MORENO, } \\
\text { Nádina Aparecida, CRUZ, } \\
\text { Vilma Aparecida Gimenes } \\
\text { da }\end{array}$ & 1999 & Artigo & Biblioteconomia & Informação\&Informação. \\
\hline $\begin{array}{l}\text { 5) A pesquisa escolar em } \\
\text { tempo de transição: } \\
\text { estudo de caso. }\end{array}$ & $\begin{array}{l}\text { BIANCARDI, Alzinete Maria } \\
\text { Rocon; GONÇALVES, } \\
\text { Andréia Carla; ESPÍRITO } \\
\text { SANTO, Eliana Lima }\end{array}$ & 2000 & $\begin{array}{l}\text { Trabalho de } \\
\text { evento }\end{array}$ & Biblioteconomia & $\begin{array}{l}\text { Congresso Brasileiro de } \\
\text { Biblioteconomia e } \\
\text { Documentação. }\end{array}$ \\
\hline $\begin{array}{l}\text { 6) Pesquisa escolar nas sé- } \\
\text { ries iniciais do ensino } \\
\text { fundamental: bases pa- } \\
\text { ra um desempenho } \\
\text { interativo entre sala de } \\
\text { aula e biblioteca es- } \\
\text { colar. }\end{array}$ & $\begin{array}{l}\text { NEVES, lara Conceição } \\
\text { Bitencourt }\end{array}$ & 2000 & $\begin{array}{l}\text { Tese, publicada } \\
\text { posteriormente } \\
\text { como artigo } \\
\text { (Neves, 2000a, } \\
\text { 2000b) }\end{array}$ & $\begin{array}{l}\text { Ciência da } \\
\text { Informação e } \\
\text { Documentação }\end{array}$ & $\begin{array}{l}\text { Programa de Pós-Graduação em } \\
\text { Ciência da Informação, Universi- } \\
\text { dade de São Paulo. }\end{array}$ \\
\hline $\begin{array}{l}\text { 7) O bibliotecário como } \\
\text { sujeito ativo no pro- } \\
\text { cesso de ensino- } \\
\text {-aprendizagem através } \\
\text { da pesquisa escolar: } \\
\text { proposta de um } \\
\text { modelo. }\end{array}$ & $\begin{array}{l}\text { FAQUETI, Marouva } \\
\text { Fallgater }\end{array}$ & 2002 & Dissertação & $\begin{array}{l}\text { Engenharia de } \\
\text { Produção }\end{array}$ & $\begin{array}{l}\text { Programa de Pós-Graduação em } \\
\text { Engenharia de Produção, Univer- } \\
\text { sidade Federal de Santa Catarina. }\end{array}$ \\
\hline $\begin{array}{l}\text { 8) A formação do pesqui- } \\
\text { sador juvenil: um estu- } \\
\text { do sob o enfoque da } \\
\text { competência informa- } \\
\text { cional. }\end{array}$ & $\begin{array}{l}\text { FIALHO, Janaína Ferreira } \\
\text { Autoria }\end{array}$ & 2004 & Dissertação & $\begin{array}{l}\text { Ciência da } \\
\text { Informação }\end{array}$ & $\begin{array}{l}\text { Escola de Ciência da Informação, } \\
\text { Universidade Federal de Minas } \\
\text { Gerais. }\end{array}$ \\
\hline $\begin{array}{l}\text { 9) A pesquisa escolar co- } \\
\text { mo elemento integra- } \\
\text { dor dos recursos de } \\
\text { biblioteca, Internet e } \\
\text { sala deaula paraacons- } \\
\text { trução do conheci- } \\
\text { mento. }\end{array}$ & NEUNZIG, Vanessa Luiz & 2004 & Dissertação & $\begin{array}{l}\text { Engenharia de } \\
\text { Produção }\end{array}$ & $\begin{array}{l}\text { Programa de Pós-Graduação em } \\
\text { Engenharia de Produção, Univer- } \\
\text { sidade Federal de Santa Catarina. }\end{array}$ \\
\hline
\end{tabular}


Quadro 1. Características dos relatos em ordem cronológica.

\begin{tabular}{|c|c|c|c|c|c|c|}
\hline & Título & Autoria & Ano & $\begin{array}{l}\text { Forma de } \\
\text { publicação }\end{array}$ & Área & $\begin{array}{c}\text { Origem } \\
\text { (curso, periódico ou evento) }\end{array}$ \\
\hline 10) & $\begin{array}{l}\text { Biblioteca escolar e a } \\
\text { orientação à pesquisa } \\
\text { bibliográfica: a si- } \\
\text { tuação na rede públi- } \\
\text { ca de ensino. }\end{array}$ & PEREIRA, Susy dos Santos & 2004 & $\begin{array}{l}\text { Trabalho de } \\
\text { evento }\end{array}$ & Biblioteconomia & $\begin{array}{l}\text { Seminário Biblioteca Escolar } \\
\text { Espaço de Ação Pedagógica. }\end{array}$ \\
\hline 11) & $\begin{array}{l}\text { Informação como } \\
\text { conhecimento: a prá- } \\
\text { tica de trabalhos com } \\
\text { projetos. }\end{array}$ & FELTRIN, Arlete da Silva & 2004 & Dissertação & Educação e Cultura & $\begin{array}{l}\text { Programa de Pós-Graduação em } \\
\text { Educação e Cultura, Universida- } \\
\text { de do Estado de Santa Catarina. }\end{array}$ \\
\hline 12) & $\begin{array}{l}\text { Representações de } \\
\text { professores e alunos } \\
\text { sobre pesquisa esco- } \\
\text { lar: a leitura crítica, a } \\
\text { escrita autônoma e a } \\
\text { formação do conhe- } \\
\text { cimento. }\end{array}$ & $\begin{array}{l}\text { STEFANO, Leizy Regina } \\
\text { Fracasso }\end{array}$ & 2005 & $\begin{array}{l}\text { Dissertação, } \\
\text { publicada } \\
\text { posteriormente } \\
\text { como artigo } \\
\text { (Stefano, 2006) }\end{array}$ & Letras & $\begin{array}{l}\text { Programa de Pós-Graduação em } \\
\text { Letras Universidade Estadual de } \\
\text { Maringá. }\end{array}$ \\
\hline 13) & $\begin{array}{l}\text { A pesquisa escolar no } \\
\text { processo ensino- } \\
\text {-aprendizagem: ava- } \\
\text { liando limites e pos- } \\
\text { sibilidades. }\end{array}$ & $\begin{array}{l}\text { ALMEIDA, Siderly do Carmo } \\
\text { Dahle de }\end{array}$ & 2006 & $\begin{array}{l}\text { Dissertação, } \\
\text { publicada } \\
\text { posteriormente } \\
\text { como artigo } \\
\text { (Portilho \& } \\
\text { Almeida, 2008) }\end{array}$ & Educação & $\begin{array}{l}\text { Programa de Pós-Graduação em } \\
\text { Educação, Pontifícia Universi- } \\
\text { dade Católica do Paraná. }\end{array}$ \\
\hline 14) & $\begin{array}{l}\text { WebQuest: uma me- } \\
\text { todologia para a pes- } \\
\text { quisa escolar por } \\
\text { meio da Internet. }\end{array}$ & SILVA, Karine Xavier Soares & 2006 & Dissertação & Educação & $\begin{array}{l}\text { Programa de Pós-Graduação } \\
\text { stricto sensu em Educação, } \\
\text { Pontifícia Universidade Católica } \\
\text { de Brasília. }\end{array}$ \\
\hline 15) & $\begin{array}{l}\text { O uso das tecnologias } \\
\text { na pesquisa escolar } \\
\text { como apoio no pro- } \\
\text { cessodeensino-apren- } \\
\text { dizagem no ensino } \\
\text { fundamental. }\end{array}$ & $\begin{array}{l}\text { BURLAMAQUI, Elizabete } \\
\text { Romero }\end{array}$ & 2007 & Dissertação & Educação & $\begin{array}{l}\text { Universidade Estácio de Sá - Rio } \\
\text { de Janeiro. }\end{array}$ \\
\hline 16) & $\begin{array}{l}\text { Representações so- } \\
\text { ciais de professores } \\
\text { sobre a pesquisa es- } \\
\text { colar. }\end{array}$ & $\begin{array}{l}\text { CARVALHO, Edilson } \\
\text { Gonçalves de }\end{array}$ & 2007 & Dissertação & Educação & $\begin{array}{l}\text { Programa de Estudos Pós- } \\
\text {-Graduados em Educação: Psi- } \\
\text { cologia da Educação, Pontifícia } \\
\text { Universidade Católica de São } \\
\text { Paulo. }\end{array}$ \\
\hline 17) & $\begin{array}{l}\text { A pesquisa escolar em } \\
\text { tempos de Internet: } \\
\text { conectando escola, } \\
\text { educadore educando. }\end{array}$ & OLIVEIRA, Carla Ariella de & 2008 & Dissertação & Educação & $\begin{array}{l}\text { Programa de Pós-Graduação em } \\
\text { Educação, Universidade Federal } \\
\text { do Paraná. }\end{array}$ \\
\hline 18) & $\begin{array}{l}\text { Mediação do bibliote- } \\
\text { cário na pesquisa es- } \\
\text { colar face à crescente } \\
\text { virtualização da infor- } \\
\text { mação. }\end{array}$ & $\begin{array}{l}\text { BICHERI, Ana Lúcia Antunes } \\
\text { de Oliveira }\end{array}$ & 2008 & Dissertação & Ciência da Informação & $\begin{array}{l}\text { Programa de Pós-Graduação em } \\
\text { Ciência da Informação, UNESP, } \\
\text { Marília. }\end{array}$ \\
\hline 19) & $\begin{array}{l}\text { Pedagogia de proje- } \\
\text { tos na biblioteca es- } \\
\text { colar: proposta de um } \\
\text { modelo para o pro- } \\
\text { cesso da pesquisa } \\
\text { escolar. }\end{array}$ & $\begin{array}{l}\text { CASTRO, César Augusto; } \\
\text { SOUZA, Maria Conceição } \\
\text { Pereira de }\end{array}$ & 2008 & Artigo & Ciência da Informação & $\begin{array}{l}\text { Perspectivas em Ciência da Infor- } \\
\text { mação. }\end{array}$ \\
\hline
\end{tabular}


Quadro 1. Características dos relatos em ordem cronológica.

\begin{tabular}{|c|c|c|c|c|c|c|}
\hline & Título & Autoria & Ano & $\begin{array}{l}\text { Forma de } \\
\text { publicação }\end{array}$ & Área & $\begin{array}{c}\text { Origem } \\
\text { (curso, periódico ou evento) }\end{array}$ \\
\hline 20) & $\begin{array}{l}\text { A busca de informa- } \\
\text { ção na Internet: bi- } \\
\text { bliotecários e estu- } \\
\text { dantes de Ensino Mé- } \\
\text { dio de escolas parti- } \\
\text { culares de Itajaí e Flo- } \\
\text { rianópolis. }\end{array}$ & ABE, Veridiana & 2009 & Dissertação & Ciência da Informação & $\begin{array}{l}\text { Programa de Pós-Graduação em } \\
\text { Ciência da Informação, Centro de } \\
\text { Ciências da Educação, Universi- } \\
\text { dade Federal de Santa Catarina. }\end{array}$ \\
\hline 21) & $\begin{array}{l}\text { Pesquisa escolar na } \\
\text { educação básica: dis- } \\
\text { curso de bibliote- } \\
\text { cários catarinenses. }\end{array}$ & GARCEZ, Eliane Fioravante & 2009 & Dissertação & Ciência da Informação & $\begin{array}{l}\text { Programa de Pós-Graduação em } \\
\text { Educação, Universidade Federal } \\
\text { de Santa Catarina. }\end{array}$ \\
\hline 22) & $\begin{array}{l}\text { Pesquisa escolar em } \\
\text { tempos de cibercul- } \\
\text { tura: ensinando Mate- } \\
\text { mática com o auxílio } \\
\text { da Internet. }\end{array}$ & $\begin{array}{l}\text { DIEDRICH, Roberta } \\
\text { Campani }\end{array}$ & 2009 & Dissertação & $\begin{array}{l}\text { Educação em Ciência } \\
\text { e Matemática }\end{array}$ & $\begin{array}{l}\text { Programa de Pós-Graduação em } \\
\text { Educação em Ciências e Mate- } \\
\text { mática, Pontifícia Universidade } \\
\text { Católica do Rio Grande do Sul. }\end{array}$ \\
\hline 23) & $\begin{array}{l}\text { Aprendizagem pela } \\
\text { pesquisa: busca e uso } \\
\text { de informações na } \\
\text { produção de conhe- } \\
\text { cimento. }\end{array}$ & CAMPELLO, Bernadete etal & 2010 & $\begin{array}{l}\text { Trabalho de } \\
\text { evento }\end{array}$ & Ciência da Informação & $\begin{array}{l}\text { Encontro Nacional de Pesquisa } \\
\text { em Ciência da Informação. }\end{array}$ \\
\hline 24) & $\begin{array}{l}\text { Fazendo pesquisa es- } \\
\text { colar na Internet. }\end{array}$ & TEIXEIRA, Sandra Areias & 2011 & Dissertação & Linguística Aplicada & $\begin{array}{l}\text { Programa de Pós-Graduação em } \\
\text { Estudos Linguísticos, Faculdade } \\
\text { de Letras, Universidade Federal } \\
\text { de Minas Gerais. }\end{array}$ \\
\hline
\end{tabular}

Fonte: Elaborada pelas autoras (2015).

pesquisa; Falta de orientação pelo professor e pelo bibliotecário, ou precariedade dessa orientação; Prática recorrente da cópia pelos alunos; Falta de preparo do professor e do bibliotecário para orientar a pesquisa; Falta de preparo do aluno para empreender a pesquisa; Falta de interação entre bibliotecário e professor; Insuficiência das avaliações acerca da pesquisa efetuada; Falta de orientação para uso da Internet - como se discute a seguir.

Dez estudos constataram o malogro da pesquisa escolar como estratégia didática, conclusão que esteve presente desde o mais antigo (Machado, 1989, p.86), cujos resultados mostraram "uma aprendizagem deficiente, por parte do escolar", até o mais recente, que verificou que "[...] a maioria dos alunos entende pesquisa como busca de informações, nem sempre a maneira como o professor solicita a pesquisa incita o posicionamento crítico dos alunos e que os textos produzidos por esses alunos costumam ser cópias" (Teixeira, 2011, p.6).
Os pesquisadores reforçaram as características negativas do processo e as dificuldades para superá-las, fato já enfatizado pelo título da conclusão do estudo mais antigo:"Pesquisa escolar: um problema que dura e perdura" (Machado, 1989, p.86). A presente análise constatou a existência de uma teia de questões que se entrelaçam e que revelam causas e consequências desse malogro.

\section{Falta de questionamento}

Os estudos mostraram que os problemas da pesquisa escolar tinham início com a maneira como ela era proposta pelos professores, que se limitavam a sugerir temas escolhidos por eles próprios (Oliveira, 2008) e desvinculados da realidade dos alunos (Machado, 1989).

A ausência de questionamento parece levar a um dos pontos também recorrentes nos estudos analisados: a falta de motivação dos alunos para realizar a pesquisa. 


\section{Falta de motivação do aluno para a pesquisa}

Esse foi outro problema identificado com frequência nos estudos da área de Educação e se apresentou como desinteresse dos alunos para a realização da pesquisa e de leituras (Feltrin, 2004; Stefano, 2005; Almeida, 2006; Carvalho, 2007; Teixeira, 2011).

Carvalho (2007) observou que

[...] mesmo nos casos em que os professores descrevem a realização da pesquisa de forma estruturada, relatam ainda a presença de educandos desmotivados, revelando, assim, que a complexidade das relações entre motivação, pesquisa escolar e processo de ensino e aprendizagem não está articulada de forma a esses professores poderem compreendê-las e estruturá-las para aplicar na sua prática pedagógica (Carvalho, 2007, p.77)

O desinteresse estava relacionado principalmente ao fato de que os professores geralmente não problematizavam o tema (Oliveira, 2008), nem se preocupavam em selecionar assuntos relacionados à vivência dos estudantes (Oliveira, 2008), além da orientação falha e falta de materiais adequados de pesquisa (Carvalho, 2007).

Para despertar o interesse, os professores lançavam mão da leitura de textos (Stefano, 2005; Campello, 2010) e estímulo à consulta a textos variados (Almeida, 2006). A utilização de materiais adequados ao perfil dos estudantes foi citada como fator motivador no estudo de Silva (2006), que também constatou que a solicitação de tarefas autênticas e realistas serviu de motivação e estímulo aos estudantes (Silva, 2006).

Em estudos que investigaram o uso da Internet, a tecnologia mostrou ser um fator de aumento da motivação (Burlamaqui, 2007; Diedrich, 2009; Silva, 2006) e tornou a pesquisa escolar mais atrativa e prazerosa. "O uso do hipertexto, a interatividade, velocidade e praticidade são os principais atrativos citados pelos alunos quando buscam a fonte eletrônica para a prática da pesquisa escolar" (Fialho, 2004, p.59)." [...] a pesquisa escolar com a utilização das mídias e das tecnologias permite uma aprendizagem prazerosa e a atividade colaborativa" (Burlamaqui, 2007, p.7).

A motivação apareceu também relacionada à busca de informações, como no estudo de Abe (2009), que verificou que o interesse do aluno aumentava à me- dida que ele encontrava informações para concluí-lo, conforme comprovado no modelo de Kuhlthau (2004).

\section{Falta/precariedade da orientação pelo professor e pelo bibliotecário}

A precariedade da orientação, mencionada também como mediação, acompanhamento ou intervenção, é outra questão recursiva: "Novamente, parece que ainda é vigente a prática de se solicitar uma pesquisa ao aluno sem Ihe dar nenhuma orientação a não ser um tema" (Teixeira, 2011, p.83). A orientação foi considerada por Faquetti (2002) como fundamental para o êxito do trabalho: "O acompanhamento individualizado das equipes na elaboração escrita foi determinante para que os alunos concluíssem seus trabalhos", e sua falta "repercutiu diretamente em dificuldades na etapa seguinte [...]" (Faquetti, 2002, p.119).

Falhas no processo de orientação apareceram, tanto na perspectiva dos professores como da biblioteca, concretizadas no fato de os alunos se sentirem"perdidos, sem saber mesmo o que copiar do material disponível" (Machado, 1989, p.65).

No caso dos professores, a falha se revelou no comportamento daqueles que não acompanhavam, não revisavam, ou não discutiam o trabalho com os alunos (Neves, 2000a). No estudo de Almeida (2006, p.96),"41\% dos alunos da escola particular e 47,6\% da pública" afirmaram que o professor apenas pedia a pesquisa e a avaliava. Foi também observada falta de orientação nos pontos em que havia maior dificuldade dos estudantes: "Percebeu-se que, na etapa de elaboração do texto final, foram deixadas de lado intervenções que constituíam oportunidade de ajudar os alunos no aspecto em que sentiram maior dificuldade: ligar as partes copiadas" (Campello, 2010, p.18).

No estudo de Carvalho (2007), os professores reconheciam que precisavam investir mais no processo, mas isso acabava não ocorrendo, segundo eles próprios, em função de alguns entraves: pouco tempo despendido para orientar e número excessivo de horas-aula que ministravam.

Com relação à biblioteca, os estudos mostraram que os alunos ali chegavam"sem orientação alguma" (Pereira, 2004, p.12). Essa queixa frequente dos bibliotecários 
pode ser explicada pelo fato de se entender que "cabe ao professor orientar o aluno no modo correto da busca do conhecimento" (Oliveira et al., 1999, p.48). Nesse sentido, Neves (2000a, p.128) também verificou que:

No entender de professores, bibliotecários e atendentes da biblioteca, em relação à pesquisa bibliográfica, a função da sala de aula é provocar a curiosidade, o interesse, a dúvida, a contradição sobre um assunto ou, até despertar a vontade dos alunos para irem à biblioteca da escola em busca de informações sobre aspectos ou tópicos trabalhados ou não como conteúdos programáticos.

Além de reconhecerem falhas na orientação dos professores, os estudos da área de Biblioteconomia/Ciência da Informação revelaram também inadequações na orientação esperada da biblioteca:

A função do encarregado [da biblioteca] limita-se [...] a fornecer um único livro ou outro, já com as páginas marcadas, levando o aluno à realização das cópias. Os encarregados [...] até disponibilizam diversos materiais para a realização dos trabalhos dos alunos, mas não os orientam a estruturar o seu trabalho (Pereira, 2004, p.12).

[...] a orientação prestada aos alunos pelo pessoal da biblioteca no que se refere ao procedimento de busca de informações junto às fontes, usualmente se resume em: identificar as obras que tratam do assunto solicitado, localizar tais obras no acervo da biblioteca, oferecê-las aos alunos, mostrando-lhes inclusive o local exato onde poderão ser encontradas, nas referidas obras, as informações significativas para eles, adverti-los de que deverão ler e resumir o texto, escrever a síntese das idéias principais dos autores lidos e elaborar a referência bibliográfica das obras consultadas, registrando-as ao final do texto a ser apresentado ao professor (Neves, 2000a, p.144).

Essas "advertências", entretanto, pouco resultado pareciam trazer, pois, segundo a citada autora, "Assustados ou aborrecidos com a extensão da tarefa que têm diante de si, os alunos dificilmente cumprem o recomendado pelo pessoal da biblioteca" (Neves, 2000a, p.144).

Ainda no que diz respeito à orientação dada na biblioteca, Bicheri (2008) encontrou situações contrastantes. De um lado, havia bibliotecários que deixavam os alunos "soltos", isentando-se da responsabilidade de orientá-los, já que esses alunos buscavam informações diretamente na Internet sem pedir ajuda do bibliotecário ou do professor. De outro, a autora encontrou bibliotecários que:

[...] conscientes da importância da mediação na formação de alunos/pesquisadores, em parceria com os professores, orientam todos os alunos quanto à pesquisa e procuram acompanhá-los pelo menos até que possuam as habilidades necessárias para realização da pesquisa de maneira independente (Bicheri, 2008, p.172).

Percebeu-se que a possibilidade de orientação do bibliotecário estava limitada aos alunos que iam à biblioteca ou solicitavam ajuda a partir de outros locais da escola, não havendo esquemas formais de comunicação com os alunos em outros ambientes fora da escola (Bicheri, 2008).

A substituição da orientação por um roteiro, testada no estudo de Pécora (1998), não se mostrou adequada, devido à dificuldade de leitura e compreensão das regras por parte dos alunos. Entretanto, a pesquisadora observou que:

Apesar de o Roteiro, como instrumento de autonomia dos estudantes em seus trabalhos, não ter conseguido o sucesso esperado, verificamos que este, precedido de orientação, alcançou resultados importantes, havendo mudança de comportamento dos sujeitos nas diferentes situações da pesquisa (Pécora, 1998, p.96).

Por outro lado, quando o roteiro tomou a forma de um aplicativo tecnológico (WebQuest), os resultados relatados foram positivos (Silva, 2006).

\section{Prática da cópia}

A prática da cópia, condenada pelos professores (Almeida, 2006), foi outro aspecto recorrente, mencionado desde o estudo mais antigo, que constatou que "De posse do material bibliográfico [...] 95\% dos sujeitos copiam o texto no todo ou em partes [...]" (Machado, 1989, p.69). Alguns estudos apenas constataram a ocorrência de cópia.

Em síntese, podemos dizer que a conduta passiva de copiar ou reproduzir textos é uma situação muito comum, e o mais grave é que, para a professora, as cópias são consideradas como 'boas' e/ou'excelentes' produções dos alunos (Biancardi et al., 2000, p.13). 
Entretanto, 11,7\% deles [professores], mesmo constatando a relevância do ato de pesquisar, reclamaram das cópias feitas, que comprometem o aproveitamento dos resultados da pesquisa pelo aluno"; [...] 23,3\% dos alunos reconheceram copiar partes do texto, mas se preocupam em citar o nome do autor, enquanto 11,6\% deixam de citar a fonte (Stefano, 2005, p.76).

A questão da cópia se mostrou evidente na fala dos educadores principalmente com relação ao uso da Internet, pois os educandos ou copiam e colam em um editor de textos as informações contidas no primeiro site que aparece na lista, ou acabam fazendo uma compilação de textos retirados de vários sites por meio do recurso do $C T R L+C, C T R L+V$, sem ao menos lerem o que copiaram (Oliveira, 2008, p.108).

Estudos mais recentes já buscaram entender como essa prática ocorria. Campello et al. (2010, p.19) explicaram a cópia de trechos como um "retrato" do caminho percorrido pelo leitor, que constituiria uma "construção em co-autoria com outros autores". Teixeira (2011) ponderou que a cópia não era intencional, constituindo um recorte das informações consideradas mais importantes pelos alunos; geralmente eles tentavam articulá-las, mas não conseguiam usar os mecanismos necessários para isso. Essa é uma das razões que explicaram por que os alunos copiavam: os professores pediam algo que eles ainda não tinham capacidade para realizar (ler, interpretar, articular ideias, comparar informações, produzir um texto). Observou-se, portanto, uma contradição: os professores reclamavam da cópia, mas não aproveitavam a pesquisa escolar para ensinar as habilidades necessárias para evitá-la e para levar o aluno a futuramente pesquisar com autonomia (Carvalho, 2007; Campello et al., 2010).

Alguns estudos mostraram possibilidades de evitar essa prática: trabalhar a pesquisa escolar na perspectiva de questionamento, e não de temas (Almeida, 2006); solicitar produtos autênticos (Silva, 2006); esclarecer sobre o significado do plágio (Diedrich, 2009); realizar a pesquisa na escola, e não fora do horário escolar (Burlamaqui, 2007); trabalhar em parceria professor/ bibliotecário (Bicheri, 2008; Garcez, 2009); exigir a estruturação lógica do trabalho; e apresentá-lo para os colegas (Oliveira, 2008).

\section{Falta de preparo do professor e do bibliotecário} para orientar a pesquisa

As falhas na orientação, explicadas pela escassez de tempo e pela sobrecarga do professor, foram também motivadas pelo desconhecimento por parte dos mediadores - tanto professores como bibliotecários - de estratégias para orientar o processo. Nesse sentido, Machado (1989, p.92) observou que "[...] nenhum deles [professores e bibliotecários] recebeu, ao longo do processo de sua formação profissional, preparação ou orientação adequadas para o desempenho dessa importante tarefa", fato observado também por Almeida (2006) e Pereira (2004).

Reafirmando o desconhecimento do professor acerca da própria concepção da pesquisa escolar e de sua metodologia, Carvalho (2007) analisou a questão específica desse despreparo em relação às tecnologias:

[Os professores] afirmam que os educandos não sabem utilizá-las [as tecnologias] de forma eficiente. No entanto, o que se observa com esses argumentos é que, de certa forma, [os professores] ocultam suas próprias dificuldades em utilizar e orientar o uso desses recursos, não percebendo a urgência de novas aprendizagens em diferentes tecnologias (Carvalho, 2007, p.78, grifos nossos).

Burlamaqui (2007) observou que os professores também apresentavam dificuldade para lidar com o excesso de informações disponíveis na Internet, quando tinham que auxiliar o aluno a escolher o material para a pesquisa.

Outro aspecto do despreparo dos mediadores foi mencionado por Neunzig (2004), que mencionou o fato de os professores não compreenderem a biblioteca como espaço de aprendizagem, atribuindo essa distorção à sua formação que "ainda não contempla a biblioteca como suporte para o processo de ensino/aprendizagem". Neves (2000a, p.133) já havia levantado a questão e mostrou que isso também acontecia na perspectiva da formação do bibliotecário.

[...] os currículos dos cursos de formação de professores (nível médio e superior) não incluem disciplina específica sobre a dinâmica e/ou o uso da BE no processo de ensino/aprendizagem. No curso de biblioteconomia a situação se inverte: não há disciplinas voltadas para a questão peda- 
gógica do uso da biblioteca escolar (Neves, 2000a, p.133).

Essa distância entre professor e bibliotecário dificulta a colaboração, conforme será visto à frente.

\section{Falta de preparo do aluno para a pesquisa}

A falta de preparo do aluno para realizar a pesquisa foi outro fator que contribuiu para o fracasso da pesquisa escolar como estratégia de aprendizagem. 0 desconhecimento das etapas foi observado por Oliveira (1999) e por Neves (2000a). Dificuldades específicas no que diz respeito à busca de informações foram relatadas por Abe (2009) e por Bicheri (2008), que observou que "alguns alunos tinham dificuldade em encontrar o assunto por procurá-lo com as'palavras pronunciadas pelo professor'"'(Bicheri, 2008, p.102).

O não domínio pelos estudantes de habilidades básicas de aprendizagem foi outra dificuldade observada por Teixeira (2011) e por Campello et al. (2010).

Carvalho (2007) analisou o pouco uso da pesquisa escolar pelos professores, pelo fato de os alunos não saberem executá-la, considerando que os professores ocultavam a importância do seu papel em ensiná-la, revelando uma solicitação de ajuda em sua formação continuada.

\section{Interação entre bibliotecário e professor}

Estudos da área de Biblioteconomia/Ciência da Informação reclamam da falta de interação entre bibliotecário e professor. Sabe-se que a colaboração entre esses dois agentes é necessária para que a pesquisa escolar seja realizada de forma eficaz. Bicheri (2008) e Garcez (2009) inclusive concluíram que a prática da cópia pode ser minimizada quando há colaboração. Mas ela é problemática, e segundo Neves (2000a, p.131), "[...] as relações entre o pessoal da biblioteca, professores e alunos ainda estão distantes de uma interação ideal", observação também feita por Abe (2009, p.121), que considerou ser necessário "fortalecer o frágil elo entre bibliotecário e professor".

Bicheri (2008) e Garcez (2009) encontraram níveis diferentes de interação entre os participantes:
A parceria entre bibliotecário/professor na orientação e acompanhamento da pesquisa escolar encontrada neste estudo divide-se em três etapas: a) harmoniosa e com resultados promissores, b) em desenvolvimento e c) inexistente (Bicheri, 2008, p.171).

Alguns bibliotecários já avançaram e estão mais próximos do professor, trabalhando de forma mais interativa e, com isto, sentem-se mais confiantes para avançar ainda mais" (Garcez, 2009, p.197).

Dentre as razões para esse distanciamento, apontou-se que a biblioteca escolar não era reconhecida pelos professores como espaço de aprendizagem, que poucos deles a frequentavam ou acompanhavam os alunos em suas tarefas (Neves, 2000a) e que o bibliotecário, por sua vez, encontrava-se afastado do processo de pesquisa escolar (Neunzig, 2004).

O estudo de Neves (2000a) revelou uma contradição: o pessoal da biblioteca considerava que os professores deveriam estar mais presentes na biblioteca, ao passo que estes achavam que a biblioteca poderia tomar a iniciativa de propor atividades e ações conjuntas.

\section{Avaliação da pesquisa}

A questão de como a pesquisa escolar é avaliada apareceu mais nitidamente em estudos das áreas de Educação e Letras, e superficialmente nos de Biblioteconomia/Ciência da Informação, revelando que a avaliação não constitui uma grande preocupação no ambiente da biblioteca. Neves (2000a) foi uma das poucas que observou a falta de avaliação formativa no processo, tanto pelo professor quanto pelo pessoal da biblioteca: não havia preocupação de discutir o texto com os alunos nem de orientar quanto à sua revisão e reelaboração. Em alguns estudos, os professores declararam que se preocupavam em avaliar a totalidade do processo, verificando como ocorreu sua construção (Almeida, 2006; Oliveira, 2008). A avaliação privilegiava o interesse, empenho e comprometimento dos estudantes (Feltrin, 2004; Carvalho, 2007), a abordagem do tema proposto, o desenvolvimento e a sequência das ideias, a citação das fontes utilizadas, a organização formal do trabalho e a clareza da produção escrita (Stefano, 2005). 
Internet

Oito estudos focalizaram a Internet em diferentes perspectivas no contexto da pesquisa escolar. Destes, cinco (Biancardi, 2000; Neunzig, 2004; Bicheri, 2008; Abe, 2009; Teixeira, 2011) constataram que o uso da Internet por si só não resolvia os problemas recorrentes na pesquisa escolar, mostrando a pouca participação dos bibliotecários na orientação do uso da rede, já que os alunos usavam a Internet principalmente em casa. O estudo de Biancardi (2000) chamou atenção para o fato de a rede facilitar a cópia.

Diferentemente, os outros três estudos que analisaram aspectos específicos do uso da rede (Silva, 2006; Burlamaqui, 2007; Diedrich, 2009) verificaram mudanças positivas: a pesquisa escolar feita com base em recursos tecnológicos adequados constituía uma atividade prazerosa e divertida para os estudantes, incentivando sua motivação, curiosidade, autonomia e criatividade, além de evitar a dispersão na coleta de informações e facilitar a comunicação professor/aluno. Esses estudos analisaram situações em que as inovações tecnológicas estavam inseridas no projeto pedagógico da escola, com um ambiente de aprendizagem voltado para a pesquisa, além da preocupação com a orientação e o acompanhamento do processo.

\section{Conclusão}

Em seu conjunto, os estudos analisados traçaram um amplo panorama da pesquisa escolar, revelando persistentemente a contradição entre discurso e prática. Teoricamente, a pesquisa escolar era vista como uma metodologia que apresentava caminhos para a atuação efetiva do educando, valorizava suas experiências, propiciava a interação entre ele e o professor, levando a uma educação de qualidade. Entretanto, essa compreensão teórica da pesquisa como princípio educativo, baseada principalmente na visão de Pedro Demo - que teve seus livros citados em 17 dos 24 estudos aqui analisados - na maioria das vezes não foi suficiente para viabilizá-la na escola; ela constituía na verdade uma estratégia mal utilizada e quase sempre ineficaz.

Para os estudantes, o significado de pesquisar era copiar textos, uma vez que não encontravam na tarefa passada pelos professores o interesse e a orientação que os estimulassem a enfrentar as dificuldades que tinham em atender às exigências do trabalho, dificuldades essas relacionadas principalmente à falta de habilidades básicas de leitura e escrita.

Assim, os aspectos negativos levantados pelos estudos constituem um emaranhado de situações que parecem exigir, para sua equação, mais do que a"vontade de mudar"dos envolvidos diretamente no processo. Mesmo assim, acompanhando a identificação das mazelas da pesquisa escolar, os autores dos estudos não deixaram de apresentar diversas sugestões para corrigi-las, baseando-se principalmente no desejo de acertar demonstrado pelos mediadores individualmente. A possibilidade de solução institucional para o problema, com a inserção dessa estratégia no projeto político-pedagógico das escolas, reflete a necessidade de uma ação institucional para a questão da pesquisa escolar, que sustente coletivamente as mudanças imprescindíveis e os esforços da comunidade escolar para mudá-las.

A soma dos resultados dos estudos realizados em áreas distintas (Educação, Letras e Biblioteconomia/Ciência da Informação) mostrou que há uma preocupação comum em buscar conhecimento que sustente mudanças na pesquisa escolar. Parece que professores e bibliotecários estão unidos no esforço de compreender o processo em suas diversas perspectivas. Os estudos oriundos da área de Biblioteconomia/Ciência da Informação, compreensivelmente, focalizaram a biblioteca e o bibliotecário como participantes da pesquisa, revelando sua vontade de contribuir, que vem de longa data. Há neles o desejo de participar, mas há também a compreensão de que "quem dá o tom" é o professor. Assim, persiste nesses estudos o discurso da necessidade de interação, de parceria, de colaboração bibliotecário/professor, que não foi suficiente para operar mudanças na visão limitada que, em geral, o professor tinha da biblioteca e do bibliotecário como colaboradores no processo.

Assim, as fronteiras são demarcadas, tornando-se claramente perceptíveis quando se observa o lugar que a biblioteca e o bibliotecário ocupam nos nove estudos da área de Educação e de Letras: ela não parece ser considerada como elemento necessário ao processo de pesquisa, sendo mencionada esporadicamente ou mesmo completamente ignorada nesses estudos. 
Levando-se em consideração que, dos 24 relatos aqui analisados, 21 utilizaram entrevistas e questionários como instrumento de coleta de dados, pode-se dizer que seu conjunto ofereceu um panorama da percepção que os participantes tinham acerca da pesquisa escolar: os sujeitos disseram o que pensavam sobre ela ou descreveram como a realizavam. Por outro lado, oito estudos coletaram dados por meio de observação, obtendo portanto maior aproximação com o processo e chegando mais perto da perspectiva dos sujeitos. As descrições minuciosas desses estudos confirmaram problemas já verificados anteriormente.

Os estudos que focalizaram a Internet como componente da pesquisa escolar puseram "mais lenha na fogueira", e trouxeram a certeza de que será cada vez mais necessário entender como as tecnologias de informação influenciam a aprendizagem.

Considerando que as pesquisas na área de ciência da informação estão cada vez mais buscando entender o processo de aprendizagem por meio da busca e do uso de informações e que, para tanto, estão utilizando referenciais da Educação - pelo menos no que diz respeito aos estudos estrangeiros mais recentes -, conclui- se que o caminho da investigação acadêmica sobre pesquisa escolar tende a uma convergência.

A análise aqui realizada mostrou que os estudos oriundos das diferentes áreas se complementam e revelam um panorama preocupante da aprendizagem por meio da pesquisa nas escolas brasileiras. Se se considerar que a aprendizagem por meio da pesquisa e do questionamento seja um dos caminhos para formar um indivíduo crítico e autônomo, então é necessário encontrar formas de fazer com que essa estratégia seja trabalhada de forma adequada nas escolas.

Desde 1971, quando da obrigatoriedade da pesquisa nas escolas da rede pública, até 1996, quando Demo fala em educar pela pesquisa, insistindo que o profissional da educação deva ser um pesquisador e ter a pesquisa como atitude cotidiana, há um espaço de 25 anos. Hoje, passados 36 anos, a pesquisa ainda é um desafio para muitos educadores e educandos.

\section{Colaboradores}

A duas autoras contribuíram na concepção e desenho do estudo, análise de dados e redação final.

\section{Referências}

Abe, V. A busca de informação na internet: bibliotecários e estudantes de Ensino Médio de escolas particulares de Itajaí e Florianópolis. 2009. Dissertação (Mestrado em Ciência da Informação), Centro de Ciências da Educação, Universidade Federal de Santa Catarina, Florianópolis, 2009.

Almeida, S.C.D. A pesquisa escolar no processo ensino-aprendizagem: avaliando limites e possibilidades. 2006. Dissertação (Mestrado em Educação) - Programa de Pós-Graduação em Educação, Pontifícia Universidade Católica do Paraná, Curitiba, 2006.

Arnone, M.P.; Small, R.; Reynolds, R. Supporting inquiry by identifying gaps in student confidence: Development of a measure of perceived competence. School Libraries Worldwide, v.16, n.1, p.47-60, 2010.

Bejes, N.C.; Dias, M.S. Orientação de pesquisa bibliográfica sistematizada em bibliotecas escolares. In: Congresso Brasileiro de Biblioteconomia e Documentação, 7., 1973, Belém. Anais... Belém: IBICT, 1973. p.292-297.

Biancardi, A.M.R.; Gonçalves, A.C.; Espírito Santo, E.L. A pesquisa escolar em tempo de transição: estudo de caso. In: Congresso Brasileiro de Biblioteconomia e Documentação, 19., Porto Alegre. Anais... Porto Alegre: 2000. 1 CD-ROM.
Bicheri, A.L.A.O. Mediação do bibliotecário na pesquisa escolar face a crescente virtualização da informação. 2008. Dissertação (Mestrado em Ciência da Informação) - Faculdade de Filosofia e Ciências, Universidade Estadual Paulista, Marília, 2008.

Burlamaqui, E.R. O uso das tecnologias na pesquisa escolar como apoio no processo de ensino-aprendizagem no ensino fundamental. 2007. Dissertação (Mestrado em Educação) Universidade Estácio de Sá, Rio de Janeiro, 2007.

Campello, B. A função educativa da biblioteca escolar no Brasil: perspectivas para seu aperfeiçoamento. In: Encontro Nacional de Pesquisa em Ciência da Informação, 5., 2003, Belo Horizonte. Anais... Belo Horizonte: Escola de Ciência da Informação da UFMG, 2003. 1 CD-ROM.

Campello, B. et al. Literatura em biblioteca escolar: características de citações de teses e dissertações brasileiras. Transinformação, v.19, n.3, p.227-236, 2007.

Campello, B.S. et al. Aprendizagem pela pesquisa: busca e uso de informações na produção de conhecimento. In: Encontro Nacional de Pesquisa em Ciência da Informação, 11.,2010, Rio de Janeiro. Anais eletrônicos... Rio de Janeiro: UFF, 2010. Disponível em: <http://repositorios.questoesemrede.uff.br/ repositorios/bitstream/handle/123456789/1323/ Aprendizagem\%20-\%20Campello.pdf? sequence=1 > . Acesso em: 18 jan. 2015. 
Carvalho, E.G. Representações sociais de professores sobre a pesquisa escolar. 2007. Dissertação (Mestrado em Educação) Programa de Estudos Pós-Graduados em Educação: Psicologia da Educação, Pontifícia Universidade Católica de São Paulo, São Paulo, 2007.

Carvalho, M.C. Educação de usuários em bibliotecas escolares: considerações gerais. Revista de Biblioteconomia de Brasília, v.9, n.1, p.22-29, 1981

Castro, C.A.; Souza, M.C.P.Pedagogia de projetos na biblioteca escolar: proposta de um modelo para o processo da pesquisa escolar. Perspectivas em Ciência da Informação, v.13, n.1, p.134-151, 2008.

Crow, S.R. Relationships that foster intrinsic motivation for information seeking. School Libraries Worldwide, v.15, n.2, p.91-112, 2009.

Cuartas, E.G.D.; Gatti, G.M. Audiovisual para treinamento de usuários em bibliotecas escolares. In: Congresso Brasileiro de Biblioteconomia e Documentação, 11., 1982, João Pessoa. Anais... João Pessoa: Associação Profissional de Bibliotecários da Paraíba, 1982. p.469-481.

Diedrich, R.C. Pesquisa escolar em tempos de cibercultura: ensinando Matemática com o auxílio da internet. 2009. Dissertação (Mestrado em Educação em Ciência e Matemática) - Faculdade de Física, Pontifícia Universidade Católica do Rio Grande do Sul, Porto Alegre, 2009.

Faqueti, M.F. O bibliotecário como sujeito ativo no processo de ensino-aprendizagem através da pesquisa escolar: proposta de um modelo. 2002. Dissertação (Mestrado em Engenharia de Produção) - Centro Tecnológico, Universidade Federal de Santa Catarina, Florianópolis, 2002.

Feltrin, A.S. Informação como conhecimento: a prática de trabalhos com projetos. 2004. Dissertação (Mestrado em Educação e Cultura) - Centro de Ciências da Educação, Universidade do Estado de Santa Catarina, Florianópolis, 2004.

Fialho, J.F. A formação do pesquisador juvenil: um estudo sob o enfoque da competência informacional. 2004. Dissertação (Mestrado em Ciência da Informação) - Escola de Ciência da Informação, Universidade Federal de Minas Gerais, Belo Horizonte, 2004

Filipenko, M. Constructing knowledge about and with informational texts: Implications for teacher-librarians working with young children. School Libraries Worldwide, v.10, n.1/2, p.21-36, 2004.

Garcez, E.F. Pesquisa escolar na educação básica: discurso de bibliotecários catarinenses. 2009. Dissertação (Mestrado em Ciência da Informação) - Centro de Ciências da Educação, Universidade Federal de Santa Catarina, Florianópolis, 2009.

Harada, V.H. Librarians and teachers as research partners: Reshaping practices based on assessment and refletion. School Libraries Worldwide, v.11, n.2, p.49-74, 2005.

Haycock, K. Collaboration: Critical success factors for student learning. School Libraries Worldwide, v.13, n.1, p. 25-35, 2007.

Kuhlthau, C. Seeking meaning: A process approach to library and information services. $2^{\text {nd }}$ ed. Westport: Libraries Unlimited, 2004.

Kuhlthau, C. Como orientar a pesquisa escolar: estratégias para o processo de aprendizagem. Belo Horizonte: Autêntica, 2010.
Laan, R.H.V.D.; Ferreira, G.I.S. Proposta de um programa de treinamento para usuário de biblioteca escolar. In: Congresso Brasileiro de Biblioteconomia e Documentação, 16., 1991, Salvador. Anais... Salvador: Associação Profissional dos Bibliotecários da Bahia, 1991. p.354-361.

Machado, A.M.N. Pesquisa escolar: uma questão para resolver. 1989. Dissertação (Mestrado em Biblioteconomia) - Faculdade de Biblioteconomia, Pontifícia Universidade Católica de Campinas, Campinas, 1989.

Montiel-Overall, P. A theoretical understanding of teacher and librarian collaboration (TLC). School Libraries Worldwide, v.11, n.2, p.24-48, 2005.

Neunzig, V.L. A pesquisa escolar como elemento integrador dos recursos de biblioteca, Internet e sala de aula para a construção do conhecimento. 2004. Dissertação (Mestrado em Engenharia de Produção) - Programa de Pós-Graduação em Engenharia da Produção, Universidade Federal de Santa Catarina, Florianópolis, 2004.

Neves, I.C.B. Pesquisa escolar nas séries iniciais do ensino fundamental: bases para um desempenho interativo entre sala de aula e biblioteca escolar. 2000. Tese (Doutorado em Ciência da Informação e Documentação) - Escola de Comunicações e Artes, Universidade de São Paulo, São Paulo, 2000a.

Neves, I.C.B. Pesquisa escolar nas séries iniciais do ensino fundamental: base para um desempenho interativo entre sala de aula e biblioteca escolar. Revista de Biblioteconomia \& Comunicação, v.8, p.91-116, 2000b.

Oliveira, C.A. A pesquisa escolarem tempos de internet: reflexões sobre essa prática pedagógica. 2008. Dissertação (Mestrado em Educação) - Setor de Educação, Universidade Federal do Paraná, Curitiba, 2008.

Oliveira, J.R.S.; Queiroz, S.L. Elaboração de um mapa de caracterização do texto científico: referenciais teóricos e aplicação em destaque. Investigações em Ensino de Ciências, v.20, n.1, p.142-166,2015. Disponível em: <http://www.if.ufrgs.br/ienci/ artigos/Artigo_ID387/v20_n1_a2015.pdf>.Acesso em: 18 jan. 2018.

Oliveira, S.M.M.; Moreno, N.A.; Cruz, V.A.G. Diagnóstico da pesquisa escolar no ensino de $5^{\mathrm{a}}$ a $8^{\mathrm{a}}$ série do $1^{\circ} \mathrm{grau}$, nas escolas de Londrina-Paraná. Informação \& Informação, v.4, n.1, p.37-50, 1999.

Pécora, G.M.M. Pesquisa na biblioteca escolar: a eficiência de um roteiro. 1998. Dissertação (Mestrado em Biblioteconomia) - Programa de Pós-Graduação em Biblioteconomia, Pontifícia Universidade Católica de Campinas, Campinas, 1998.

Pereira, S.S. Biblioteca escolar e a orientação à pesquisa bibliográfica: a situação na rede pública de ensino. In: Seminário Biblioteca Escolar Espaço de Ação Pedagógica, 3., 2004, Belo Horizonte. Anais eletrônicos... Belo Horizonte: UFMG, 2004. Disponível em: <http://gebe.eci.ufmg.br/downloads/303. pdf>. Acesso em: 18 jan. 2016.

Portilho, E.M.L.; Almeida, S.C.D. Avaliando a aprendizagem e o ensino com pesquisa no Ensino Médio. Revista Ensaio: Avaliação e Políticas Públicas em Educação, v.16, n.60, p.469-488, 2008. 
Santos, I.R. A biblioteca escolar e a atual pedagogia brasileira. Revista de Biblioteconomia de Brasília, v.1, n.2, p.145-149, 1973.

Silva, K.X.S. Webquest: uma metodologia para a pesquisa escolar por meio da internet. 2006. Dissertação (Mestrado em Educação) - Programa de Pós-Graduação em Educação, Pontifícia Universidade Católica de Brasília, Brasília, 2006.

Stefano, L.R.F. Representações de professores e alunos sobre pesquisa escolar: a leitura crítica, a escrita autônoma e a formação do conhecimento. 2005. Dissertação (Mestrado em Letras) - Centro de Ciências Humanas, Letras e Artes, Universidade Estadual de Maringá, Maringá, 2005.
Stefano, L.R.F. Representações de professores e alunos sobre pesquisa escolar: a leitura crítica, a escrita autônoma e a formação do conhecimento. Iniciação Científica CESUMAR, v.8, n.1, Esp., p.71-83, 2006.

Teixeira, S.A. Fazendo pesquisa escolar na internet. 2011. Dissertação (Mestrado em Lingüística Aplicada) - Faculdade de Letras, Universidade Federal de Minas Gerais, Belo Horizonte, 2011.

Williamson, K.; Archibald, A.; McGregor, J. Shared vision: A key to successful collaboration. School Libraries Worlwide, v.16, n.2, p.16-30, 2010. 